\title{
Kinetic and Equilibrium Study of the reaction of nitroprusside and hydroxide ions: Influence of Ionic Strength using Pitzer Model
}

\author{
Eugenia Rubín, Pilar Rodríguez, Isabel Brandariz, Manuel E. Sastre de Vicente
}

Departamento de Química Física e Ingeniería Química I, Facultad de Ciencias, Campus da Zapateira, c. Alejandro de la Sota 1, 15071 A Coruña, Spain

\begin{abstract}
A kinetic and equilibrium study of the addition reaction of hydroxide ions to nitroprusside has been carried out in this paper. Rate and equilibrium constants at different salt concentrations (up to $4 \mathrm{~mol} / \mathrm{kg}$ ) were obtained and the influence of ionic strength was studied by means of Pitzer equations. This model is of special interest because it is able to explain the experimental behaviour at high ionic strength, when Debye-Huckel limiting law is no longer valid.
\end{abstract}

\section{Introduction}

Reactions of the nitrosyl ligand bounded to transition metal centers are interesting both in their own and in relation to the biochemical background [1] and consequently have attracted a considerable research. In particular, the reactivity of Pentacyanonitrosylferrate(II) ion has been rather extensively investigated $[2,3]$ and numerous studies have been carried out in order to determine the electrophilic behaviour of this species [4-12]

The mechanism of the reaction between nitroprusside and hydroxide ions is well established [4-6] as well as those of the related processes with the ruthenium and osmium species $[13,14]$. The reaction takes place through a two-step mechanism: a rate determining attack of a hydroxide at the nitrogen, followed by the removal, by a second hydroxide, of the proton of the complex in a fast acid-base reaction.

The reactions may be written in the following form:

$$
A^{-2}+\mathrm{OH}^{-} \underset{k_{-1}}{k_{1}} \mathrm{Z}^{-3} \quad \text { slow reaction }
$$




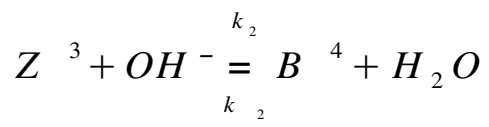

being the global process:

$$
A^{-2}+2 \mathrm{OH}^{-}=\mathrm{B}^{-4}+\mathrm{H}_{2} \mathrm{O}
$$

where stoichiometric equilibrium constant for reaction (3) will be denoted as $\mathrm{K}^{*}, \mathrm{Y}^{-3}$ will represent the activated complex for reaction (1), and we have defined

$$
\begin{aligned}
A^{-2} & =\left[\mathrm{Fe}(\mathrm{CN})_{5} \mathrm{NO}\right]^{-2} \\
Z^{-3} & =\left[\mathrm{Fe}(\mathrm{CN})_{5} \mathrm{NO}_{2} \mathrm{H}\right]^{-3} \\
B^{-4} & =\left[\mathrm{Fe}(\mathrm{CN})_{5} \mathrm{NO}_{2}\right]^{-4}
\end{aligned}
$$

The following rate equation has been deduced for the above process [5]:

$$
v=-\frac{d\left[A^{-2}\right]}{d t}=k_{o b s}\left[A^{-2}\right]
$$

where

$$
k_{o b s}=k_{1}^{*}\left(\left[O H^{-}\right]+\frac{1}{K^{*}\left[O H^{-}\right]}\right)
$$

We made a kinetic and equilibrium study of the addition reaction of $\mathrm{OH}^{-}$to $\left[\mathrm{Fe}(\mathrm{CN})_{5} \mathrm{NO}\right]^{2-}$ : the rate constant of the first step $\left(\mathrm{k}^{*}{ }_{1}\right)$ and the equilibrium constant $\left(\mathrm{K}^{*}\right)$ were determined from the value of $\mathrm{k}_{\mathrm{obs}}$. The experiments were performed at different salt concentrations and the influence of ionic strength on both constants was studied using the Pitzer equations to express the activity coefficients of the species appearing in the reactions $[15,16]$. The paper is organized as follows: in the experimental section determination of $\mathrm{k}_{\mathrm{obs}}$ is explained, in the following section $\mathrm{k}_{1}^{*}$ and $\mathrm{K}^{*}$ are obtained from $\mathrm{k}_{\mathrm{obs}}$, finally in the two next sections dependence of $\mathrm{k}^{*}{ }_{1}$ and $\mathrm{K}^{*}$ vs ionic strength is explained using Pitzer model.

\section{Experimental}

Chemicals of analytical reagent grade, without further purification, were used throughout this study. Solutions were prepared using doubly distilled water. Stock nitroprusside solutions were stored in the dark to prevent photochemical decomposition [17]. 
Reactions were carried out mixing ca. $0.5 \mathrm{~mL}$ of hydroxide, $0.2-1 \mathrm{M}$ standardized solution, ( $\mathrm{NaOH}$ for sodium salts, $\mathrm{KOH}$ for potassium salts) with ca. $3 \mathrm{~mL}$ of a solution containing $\left[\mathrm{Fe}(\mathrm{CN})_{5} \mathrm{NO}\right]^{2-}\left(2.510^{-4} \mathrm{M}\right)$, the inert electrolyte $(\mathrm{I}=0.025-3 \mathrm{M})$ and an excess of nitrite ion $(0.01 \mathrm{M})$ in order to prevent the aquation reaction of the product $\left(\left[\mathrm{Fe}(\mathrm{CN})_{5} \mathrm{NO}_{2}\right]^{4-}+\mathrm{H}_{2} \mathrm{O}=\right.$ $\left.\left[\mathrm{Fe}(\mathrm{CN})_{5} \mathrm{H}_{2} \mathrm{O}\right]^{3-}+\mathrm{NO}_{2}^{-}\right)[6]$ that could interfere with the target process (nitrite ion was added when $\mathrm{NaCl}, \mathrm{KCl}$ and $\mathrm{NaClO}_{4}$ were used)

The study of the reaction was done under pseudo first order conditions, i.e at least, a ten fold excess of $\left[\mathrm{OH}^{-}\right]$. The reaction progress was followed by monitoring the appearance of $\left[\mathrm{Fe}(\mathrm{CN})_{5} \mathrm{NO}_{2}\right]^{4-}$ at $400 \mathrm{~nm}$ with a Varian Cary 100 Bio Spectrophotometer with the cell compartment thermostated at $25 \pm 0.1^{\circ} \mathrm{C}$. Rate constants, $\mathrm{k}_{\mathrm{obs}}$ were determined fitting the absorbance versus time data to the first order exponential equation, using data corresponding to, at least, three half-lives.

\section{Results and Discussion}

\section{Determination of rate and equilibrium constants}

The values of $\mathrm{k}_{\mathrm{obs}}$ obtained in this study are listed in table 1 . The quoted rate constants have an averaged error of $\pm 0.5-2 \%$. Several electrolytes were used to keep ionic strength constant.

Dependence of $\mathrm{k}_{\mathrm{obs}} \mathrm{vs}\left[\mathrm{OH}^{-}\right]$is given by equation (5). The fitting of these data to equation 5 yields the rate $\left(\mathrm{k}^{*}{ }_{1}\right)$ and equilibrium constants $\left(\mathrm{K}^{*}\right)$. Non-linear Marquardt algorithm has been used to perform data fitting and values obtained for $\mathrm{k}_{1}{ }_{1}$ and $\mathrm{K}^{*}$ are listed in tables 2 and 3. The experimental behaviour of $\mathrm{k}_{\mathrm{obs}} \mathrm{vs}\left[\mathrm{OH}^{-}\right]$is shown in figure 1 . Different trends are observed depending on ionic strength: when salt concentration is low (open circles $\mathrm{I}=0.025 \mathrm{M}$ ) $\mathrm{k}_{\mathrm{obs}}$ decreases with $\left[\mathrm{OH}^{-}\right]$and when it is high (solid circle $\mathrm{I}=2 \mathrm{M}$ ) $\mathrm{k}_{\text {obs }}$ increases linearly with $\left[\mathrm{OH}^{-}\right]$. This pattern has been observed for all the salts used in this study and it may be understood in view of equation (5). The second term on the right-hand side of this equation, $1 / \mathrm{K}^{*}\left[\mathrm{OH}^{-}\right]$, includes the stoichiometric equilibrium constant, which depends strongly on the nature and concentration of the inert electrolyte [3] and increases with ionic strength; thus, for low values of $\mathrm{K}^{*}$ the second term in equation (5) predominates and results in a hyperbolic dependence of rate constant on $\left[\mathrm{OH}^{-}\right]$; for the higher values of ionic strength the first term prevails and a linear dependence arises. The lacking values for the equilibrium 
constant in $\mathrm{KNO}_{2}(\mathrm{I}=3 \mathrm{M})$ and $\mathrm{KCl}(\mathrm{I}=2 \mathrm{M}$ and $\mathrm{I}=3 \mathrm{M})$ is due to the impossibility of finding the $\mathrm{K}^{*}$ values that fit equation (5) because the second term it is too low to be significant.

Equilibrium and kinetic constants found in the literature are summarized in table 4, together with the corresponding ones obtained in this work. It can be seen that our data are in good agreement with the values determined by other authors.

\section{Pitzer equations for the dependence of the equilibrium constants on the ionic strength}

Equilibrium constant for reaction (3) is given by:

$$
K=\frac{\left(B^{-4}\right) a_{w}}{\left(A^{-2}\right)\left(O H^{-}\right)^{2}}=\frac{\left[B^{-4}\right]}{\left[A^{-2}\right]\left[O H^{-}\right]^{2}} \frac{\gamma_{B^{-4}} a_{w}}{\gamma_{A^{-2}} \gamma_{O H^{-}}^{2}}=K^{*} \frac{\gamma_{B^{-4}} a_{w}}{\gamma_{A^{-2}} \gamma_{O H^{-}}^{2}}
$$

where $a_{w}$ denotes water activity, $\mathrm{K}^{*}$ is the stoichiometric constant and $\gamma$ the activity coefficients of the species. Taking logarithms:

$$
-\ln K^{*}=-\ln K+\ln \gamma_{B^{-4}}+\ln a_{w}-\ln \gamma_{A^{-2}}-2 \ln \gamma_{O H^{-}}
$$

Substituting in eq(7) the activity coefficients given by Pitzer model [18,19] (see Appendix 1), the result is:

$$
\begin{gathered}
-\ln K^{*}=-\ln K+10 f^{\gamma}+10 I^{2} B_{M X}^{\prime}+2 I\left(B_{M B}-B_{M A}-2 B_{M O H}\right) \\
+2 I^{2}\left(C_{M B}-C_{M A}-2 C_{M O H}\right)+2 I\left(\theta_{X B}-\theta_{X A}-2 \theta_{X O H}\right) \\
+I^{2}\left(\psi_{M X B}-\psi_{M X A}-2 \psi_{M X O H}\right)+\ln a_{w}
\end{gathered}
$$

where MX is the inert electrolyte. Inserting $\mathrm{B}$ and $\mathrm{B}^{\prime}$ expressions, see Appendix 1, and rearranging, equation (8) becomes:

$$
\begin{aligned}
f_{\text {known } 1}= & -\ln K^{*}-10 f^{\gamma}-5 \beta_{M X}^{(1)}-\ln a_{w}=-\ln K+g\left(\beta_{M B}^{(1)}-\beta_{M A}^{(1)}-2 \beta_{M O H}^{(1)}\right) \\
& +I\left(2 \beta_{M B}^{(0)}-2 \beta_{M A}^{(0)}-4 \beta_{M O H}^{(0)}+2 \theta_{X B}-2 \theta_{X A}-4 \theta_{X O H}\right) \\
& +I^{2}\left(2 C_{M B}-2 C_{A M}-4 C_{M O H}+\psi_{M X}-\psi_{M X}-2 \psi_{M X O H}\right)
\end{aligned}
$$

which may be denoted as:

$$
f_{\text {knownl }}=A_{0}+A_{1} I+A_{2} g+A_{3} I^{2}
$$

All known terms are included in $f_{\text {knownl }}=-\ln K^{*}-10 f^{\gamma}-5 \beta_{M X}^{(1)}-\ln a_{w}$. In order to use Pitzer equations, stoichiometric constants have to be converted to molality scale since they were determined in the molar scale. Conversion between concentration scales is 
explained [20] in Appendix 2. Fitting of $f_{\text {known } 1}$ vs $g, I, I^{2}$ yields the values of $A_{1}, A_{2}$ and $A_{3}$, as well as, thermodynamic constant, $\mathrm{A}_{0}=-\ln \mathrm{K}$. All these parameters are listed in table 5 . When $\mathrm{KCl}$ or $\mathrm{KNO}_{2}$ were used as inert electrolytes, stoichiometric constants were obtained up to $\mathrm{I}=1$ $\mathrm{mol} / \mathrm{dm}^{3}$ and $\mathrm{I}=2 \mathrm{~mol} / \mathrm{dm}^{3}$ respectively, as it has been explained in the section above. In these cases, Pitzer equations have been used without quadratric terms, which are negligible at low ionic strength (less than $\mathrm{I}=2$ ). In figure 2, experimental data are shown together with fitting functions, according to Pitzer model. At low ionic strength, where Debye-Huckel limiting law is still valid, the behaviour is quite similar for all the electrolytes, however when salt concentration is increased different trends are observed. Equilibrium constants in potassium salts exhibit higher values than those in sodium salts (making their determination impossible at ionic strengths higher than 1), and it is also observed that this behaviour depends on the cation (curves for sodium salts and for potassium salts, make two clearly different groups). This is the expected behaviour because the species involved in the equilibrium bear negative charge, so they interact with cations in a greater extent than with anions.

\section{Pitzer equations for the dependence of the rate constant on the ionic strength}

The rate constant for an elemental reaction at a certain ionic strength, $\mathrm{k}_{1}{ }_{1}$, is related to the rate constant at zero ionic strength, $\mathrm{k}_{1}^{0}$, by means of the following equation [21]:

$$
k_{1}^{*}=k_{1}^{0} \frac{\gamma_{A^{-2}} \gamma_{O H^{-}}}{\gamma_{Y^{-3}}}
$$

where $\mathrm{Y}^{-3}$ represents the activated complex. Taking logarithms:

$$
\ln k_{1}^{*}=\ln k_{1}^{0}+\ln \gamma_{A^{-2}}+\ln \gamma_{O H^{-}}-\ln \gamma_{Y^{-3}}
$$

substituting the activity coefficients according to Pitzer equations (see Appendix 1)

$$
\begin{gathered}
f_{\text {known } 2}=\ln k_{1}^{*}+4 f^{\gamma}+2 \beta_{M X}^{(1)} g^{\prime}=\ln k_{1}^{0}+g\left(\beta_{M A}^{(1)}+\beta_{M O H}^{(1)}-\beta_{M Y}^{(1)}\right) \\
+I\left(2 \beta_{M A}^{(0)}+2 \beta_{M O H}^{(0)}-2 \beta_{M Y}^{(0)}+2 \theta_{X A}+2 \theta_{X O H}-2 \theta_{X Y}\right) \\
+I^{2}\left(2 C_{M A}+2 C_{M O H}-2 C_{M Y}+\psi_{M X}+\psi_{M X O H}-\psi_{M X}\right)
\end{gathered}
$$

which may be denoted as:

$$
f_{\text {known } 2}=B_{0}+B_{1} I+B_{2} g+B_{3} I^{2}
$$


All known terms are included in $f_{\text {known } 2}=\ln k_{1}^{*}+4 f^{\gamma}+2 \beta_{M X}^{(1)} g^{\prime}$. In order to use Pitzer equations, the rate constants have been converted to molality scale as it is described in Appendix 2. Fitting of $f_{\text {known2 }}$ vs $g, I, I^{2}$ yields the values of $B_{1}, B_{2}$ and $B_{3}$, as well as, the rate constants at zero ionic strength, $\mathrm{B}_{0}=\mathrm{k}^{0}{ }_{1}$. All these parameters are listed in table 6 . In figure 3 , experimental data are shown together with fitting functions, according to Pitzer model. As it was to be expected when the reacting species have the same sign, an increase in ionic strength increases the rate, with a similar behaviour for all the electrolytes. This is true at low salt concentration when limiting law is still valid [21]. However, at higher ionic strengths, when this law is not good enough to describe the dependence of activity coefficients on ionic strength, rate constants do not increase as rapid as they did (or they even decrease). Besides, their values differ from one electrolyte to another. This effect is more important the greater is the salt concentration, in this situation the use of interaction models for the activity coefficient, ie Pitzer model, is clearly needed to explain the experimental behaviour.

\section{Errors in Pitzer parameters}

Since its outset, the Pitzer approach has found wide and successful application in reproducing experimental data for complex systems. However, difficulties arise because, in some cases, the resulting intercorrelation among the variables in the regression, due to multicollinearity, may lead to highly imprecise parameter estimates, as can be seen in our case, in table 5 (parameter $\mathrm{A}_{1}$ for $\mathrm{NaClO}_{4}$ and $\mathrm{NaCl}$ ) and in table 6 (parameters $\mathrm{B}_{1}$ and $\mathrm{B}_{3}$ ). Our group and others have applied in some cases alternative procedures in order to overcome the multicollinearity problem, as, for example, ridge regression method [22-25]. However, this alternative method leads theoretically to more precise, but slightly biased estimates for the parameters in the model. In order to avoid the controversy over the performance of the ridge regression method [26], a common practice [27,28] is to simply omit some parameters in the model as it would be the case for $\mathrm{A}_{1}$ in table 5 or $\mathrm{B}_{3}$ in table 6 . 


\section{Appendix 1: Pitzer equations for activity coefficients}

In this appendix activity coefficients of the species involved in reactions (1) and (2) are expressed by means of Pitzer model. Inert electrolyte, represented by MX, is in great excess in relation to other species. If $z_{M^{+}}=1$ and $z_{X^{-}}=-1$, the ionic strength is given by $\quad I=m_{M^{+}}=m_{X^{-}}$. The activity coefficient of an ion i, bearing negative charge, $\mathrm{z}_{\mathrm{i}}$, according to Pitzer theory is giving by [18]:

$$
\ln \gamma_{i}=z_{i}{ }^{2} f^{\gamma}+2 I\left(B_{M i}+I C_{M i}\right)+2 I \theta_{i X}+I^{2}\left(z_{i}{ }^{2} B^{\prime}{ }_{M X}+z_{i} C_{M X}+\psi_{i M X}\right)
$$

where, $\mathrm{f}^{\gamma}$ is a extended form of the Debye-Hückel term that takes into account long-range interactions, and it is given, at $25^{\circ} \mathrm{C}$, by [18]:

$$
f^{\gamma}=-0.3915\left[\frac{\sqrt{I}}{1+1.2 \sqrt{I}}+\frac{2}{1.2} \ln (1+1.2 \sqrt{I})\right]
$$

B, the second virial coefficient, and its derivative, B', are defined in Pitzer theory by:

$$
\begin{aligned}
& B_{M X}=\beta_{M X}^{(0)}+\frac{\beta_{M X}^{(1)}}{2 I}\left[1-(1+2 \sqrt{I}) e^{-2 \sqrt{I}}\right]=\beta_{M X}^{(0)}+\frac{\beta_{M X}^{(1)}}{2 I} g \\
& B^{\prime}{ }_{M X}=\frac{\beta_{M X}^{(1)}}{2 I^{2}}\left[-1+(1+2 I+2 \sqrt{I}) e^{-2 \sqrt{I}}\right]=\frac{\beta_{M X}^{(1)}}{2 I^{2}} g^{\prime}
\end{aligned}
$$

where we have called $g=1-(1+2 \sqrt{I}) e^{-2 \sqrt{I}}$ and $g^{\prime}=-1+(1+2 I+2 \sqrt{I}) e^{-2 \sqrt{I}}$ The interaction parameters $\beta_{M X}^{(0)}, \beta_{M X}^{(1)}$ are specific to the compound MX, and they represent the short-range interaction in the presence of the solvent between solute particles $\mathrm{M}$ and $\mathrm{X}$. The third virial coefficient, $\mathrm{C}_{\mathrm{MX}}$, represents triple interactions MMX and XXM.

Parameter $\theta_{\mathrm{iX}}$ accounts for interactions between ions of like sign ( $\mathrm{i}$ and $\mathrm{X}$ ), which arises only for mixed solutions. The same is true for the term $\psi_{i M X}$, that it is related to the triple interactions of two similarly charged ions (i and X) with and ion of opposite charge (M).

Therefore, the activity coefficient for the ions involved in reactions (1) and (2) are:

$$
\begin{aligned}
& \ln \gamma_{O H^{-1}}=f^{\gamma}+2 I\left(B_{M O H}+I C_{M O H}\right)+2 I \theta_{X O H}+I^{2}\left(B^{\prime_{M X}}+C_{M X}+\psi_{O H M X}\right) \\
& \ln \gamma_{A^{-2}}=4 f^{\gamma}+2 I\left(B_{M A}+I C_{M A}\right)+2 I \theta_{A X}+I^{2}\left(4 B^{\prime}{ }_{M X}+2 C_{M X}+\psi_{A M X}\right) \\
& \ln \gamma_{Y^{-3}}=9 f^{\gamma}+2 I\left(B_{M Y}+I C_{M Y}\right)+2 I \theta_{Y X}+I^{2}\left(9 B^{\prime}{ }_{M X}+3 C_{M X}+\psi_{Y M X}\right) \\
& \ln \gamma_{B^{-4}}=16 f^{\gamma}+2 I\left(B_{M B}+I C_{M B}\right)+2 I \theta_{B X}+I^{2}\left(16 B^{\prime}{ }_{M X}+4 C_{M X}+\psi_{B M X}\right)
\end{aligned}
$$


On the other hand, in equation (6) it appears the activity of water, $\mathrm{a}_{\mathrm{w}}$, that is related to the osmotic coefficient, $\phi$, by the following equation [19]:

$$
\ln a_{w}=\frac{-M_{0} I}{1000} \phi
$$

where $\mathrm{M}_{0}=18$ is the molar mass of the solvent and the osmotic coefficient can be expressed by means of Pitzer theory as follows [18]:

$$
\phi-1=-0.3915\left[\frac{\sqrt{I}}{1+1.2 \sqrt{I}}\right]+I\left(\beta_{M X}^{(0)}+\beta_{M X}^{(1)} e^{-2 \sqrt{I}}\right)+I^{2} C_{M X}^{\phi}
$$

where $\mathrm{C}$ is related to $\mathrm{C}^{\phi}$ by:

$$
C_{M X}=\frac{C_{M X}^{\Phi}}{2\left|z_{M^{+}} z_{X^{-}}\right|^{1 / 2}},
$$

in salts of 1-1 valence type $z_{M^{+}}=1, z_{X^{-}}=-1$ and $C_{M X}=\frac{C_{M X}^{\Phi}}{2}$

Table 7 gives the Pitzer parameters used to calculate the osmotic coefficient and the water activity for the inert salts used in this study. 


\section{Appendix 2: Interconversion of concentration scales}

Equilibrium and rate constants have been determined using molar concentration scale, but in order to apply Pitzer equations, it is necessary to use the molality scale. The relationship between molality, $\mathrm{m}_{\mathrm{i}}$, and molarity, $\mathrm{c}_{\mathrm{i}}$, for species $\mathrm{i}$ in a solution with a density $\rho$, is expressed by the following equation:

$$
m_{i}=\frac{c_{i}}{\rho-M_{\text {salt }} c_{\text {salt }}}
$$

where $\mathbf{M}_{\text {salt }}$ is the molar mass of the salt. As it can be seen, to perform the conversion between concentration scales, density of solutions is needed. The concentration of the inert electrolyte is much higher than that of the reacting species, so density of solutions has been considered equal to that of solutions containing only the salt, that was taken from ref [20]

Taking into account last equation, stoichiometric equilibrium constant is given by:

$$
K^{*}=\frac{m_{B^{-4}}}{m_{A^{-2}} m_{O H^{-}}^{2}}=\frac{c_{B^{-4}}}{c_{A^{-2}} c_{O H^{-}}^{2}}\left(\rho-M_{\text {salt }} c_{\text {salt }}\right)^{2}=K_{c}^{*}\left(\rho-M_{\text {salt }} c_{\text {salt }}\right)^{2}
$$

where $\mathrm{K}^{*}$ is the constant in the molal scale and $\mathrm{K}_{\mathrm{c}}{ }^{*}$ is the corresponding one in the molar scale.

Taking logarithms: $\quad \log K^{*}=\log K_{c}^{*}+2 \log \left(\rho-M_{\text {salt }} c_{\text {salt }}\right)$

The conversion equation for rate constant may be obtained by similar reasoning:

$$
\log k_{1}^{*}=\log k_{l c}^{*}+\log \left(\rho-M_{\text {salt }} c_{\text {salt }}\right)
$$

where $\mathrm{k}^{*}$ is the constant in the molal scale and $\mathrm{k}_{\mathrm{c}}{ }^{*}$ is in the molar scale. 


\section{References}

1. Butler, A. R.; Glidewell, C. Chem Soc Rev 1987, 16, 361.

2. Bottomley, F. Acc Chem Res 1978, 11, 158.

3. Swinehart, J. H. Coord Chem Rev 1967, 2,385.

4. Masek, J.; Dempir, J Inorg Chim Acta 1968, 2, 443.

5. Masek, J.; Wendt, H. Inorg Chim Acta 1969, 3, 455.

6. Swinehart, J. H.; Rock, P. A. Inorg Chem 1966, 5, 573.

7. Johnson, M. D.; Wilkins, R. G. Inorg Chem 1984, 23, 231.

8. Wolfe, S. K.; Andrade, C.; Swinehart, J. H. Inorg Chem 1974, 13, 2567.

9. Gutiérrez, M. M.; Amorebieta, V. T.; Estiú, G. L.; Olabe, J. A. J Am Chem Soc 2002, 124, 10307.

10. Roncaroli, F.; Olabe, J. A.; van Eldik, R. Inorg Chem 2002, 41, 5417.

11. Stochel, G.; van Eldik, R.; Stasicka, Z. Inorg Chem 1988, 27, 2767.

12. Koltoff, I. M.; Toren, P. E. J Am Chem Soc 1953, 75, 1197.

13. Chevalier, A. A.; Gentil, L. A.; Olabe, J. A. J Chem Soc Dalton Trans 1991, 1959.

14. Baraldo, L. M.; Bessega, M. S.; Rigotti, G. E.; Olabe, J. A. Inorg Chem 1994, 33, 5890.

15. Vilariño, T.; Alonso, P.; Armesto, X. L.; Rodríguez, P. Sastre de Vicente, M. E. J Chem Research (S) 1998, 558.

16. Blandamer, M. J.; Burgess, J.; Cottrell, M. R.; Hakin, A. W.; Horn, I. M.; Sanchez, F. J. Chem Soc Faraday Trans 1 1989, 85(7), 1809.

17. Stochel, G. Coord Chem Rev 1992, 114, 269.

18. Pitzer, K.S. in Activity Coefficients in Electrolyte Solutions; Pytkowicz, R. (Ed); CRC Press: Boca Raton, Fl, 1991.

19. Brandariz, I.; Fiol, S.; Sastre de Vicente, M. E. Ber Bunsenges Phys Chem 1995, 99(5), 749.

20. Sohnel, O.; Novotny, P. Densities of Aqueous Solutions of Inorganic Substances, Physical Sciences Data, 22; Elsevier: Amsterdam, 1985.

21. Laidler, K. J. Chemical Kinetics, 3rd ed.; Harper Collins Publishers: NY, 1987.

22. Van Gaans, P. F. M. J Solution Chem 1991, 20(7), 703.

23. Herrero, R.; Brandariz, I.; Fiol, S.; Vilariño, T.; Sastre de Vicente, M. E. An Quim 1993, 89(5), 602.

24. Fiol, S.; Brandariz, I., Herrero, R.; Vilariño, T.; Sastre de Vicente, M. Ber Bunsenges Phys Chem 1994, 98(2), 164.

25. Fiol, S.; Brandariz, I.; Sastre de Vicente, M. Talanta 1995, 42(6) ,797.

26. Draper, N. R.; Smith, H. Applied Regression Analysis, 2nd ed; John Wiley \& Sons: NY, 1981.

27. Pitzer, K. S.; Roy, R. N.; Silvester, F. S. J Am Chem Soc 1977, 99, 4930.

28. Barta, L.; Hepler, L. G. Can J Chem 1986, 64, 353. 
Table 1. Rate constant data, $\mathrm{k}_{\mathrm{obs}}$, see eq (5), for the reaction of nitroprusside with $\mathrm{OH}^{-}$in aqueous solution at $25^{\circ} \mathrm{C}$.

\begin{tabular}{|c|c|c|c|c|c|}
\hline $\mathrm{I} / \mathrm{mol} \mathrm{L}^{-1}$ & $\begin{array}{c}10^{3} \mathrm{x}\left[\mathrm{OH}^{-}\right] / \\
\mathrm{mol} \mathrm{L}^{-1}\end{array}$ & $10^{3} \mathrm{xk}_{\mathrm{obs}} / \mathrm{s}^{-1}$ & $\mathrm{I} / \mathrm{mol} \mathrm{L}^{-1}$ & $\begin{array}{c}10^{3} \mathrm{x}\left[\mathrm{OH}^{-}\right] / \\
\mathrm{mol} \mathrm{L}^{-1}\end{array}$ & $10^{3} \mathrm{xk}_{\mathrm{obs}} / \mathrm{s}^{-1}$ \\
\hline \multirow[t]{7}{*}{0.03} & 5.05 & 8.90 & 0.5 & 7.21 & 3.06 \\
\hline & 7.01 & 6.60 & & 14.4 & 4.94 \\
\hline & 8.98 & 5.69 & & 21.6 & 7.18 \\
\hline & 10.9 & 5.10 & & 28.8 & 9.43 \\
\hline & 12.9 & 4.84 & & 36.1 & 11.6 \\
\hline & 14.9 & 4.64 & & 43.3 & 14.0 \\
\hline & & & & 50.5 & 16.1 \\
\hline \multirow[t]{8}{*}{0.05} & 5.41 & 6.34 & & 54.1 & 17.0 \\
\hline & 10.8 & 4.46 & & & \\
\hline & 19.8 & 4.67 & 1 & 7.21 & 3.18 \\
\hline & 25.2 & 5.26 & & 14.4 & 5.55 \\
\hline & 30.6 & 6.61 & & 21.6 & 8.16 \\
\hline & 36.1 & 6.42 & & 28.8 & 10.8 \\
\hline & 39.7 & 7.04 & & 36.1 & 13.0 \\
\hline & 43.3 & 7.52 & & 43.3 & 15.7 \\
\hline \multirow[t]{8}{*}{0.1} & 3.16 & 6.48 & 2 & 7.21 & 3.71 \\
\hline & 6.31 & 4.22 & & 14.4 & 6.89 \\
\hline & 12.6 & 3.82 & & 21.6 & 10.3 \\
\hline & 18.9 & 4.58 & & 28.8 & 13.9 \\
\hline & 25.2 & 5.62 & & 36.1 & 16.7 \\
\hline & 31.6 & 6.83 & & 43.3 & 20.6 \\
\hline & 44.2 & 9.33 & & 50.5 & 24.3 \\
\hline & & & & 61.7 & 28.8 \\
\hline \multirow[t]{8}{*}{0.2} & 7.21 & 3.38 & & & \\
\hline & 18.0 & 4.87 & 3 & 5.05 & 2.93 \\
\hline & 28.8 & 7.52 & & 7.01 & 3.99 \\
\hline & 39.7 & 10.0 & & 8.98 & 5.04 \\
\hline & 50.5 & 12.1 & & 10.9 & 6.09 \\
\hline & 61.3 & 15.2 & & 12.9 & 7.41 \\
\hline & 72.1 & 17.3 & & 14.9 & 8.63 \\
\hline & 90.1 & 21.7 & & & \\
\hline
\end{tabular}


$\mathrm{KNO}_{2}$

\begin{tabular}{cccccc}
\hline $\mathrm{I} / \mathrm{mol} \mathrm{L}^{-1}$ & $\begin{array}{c}10^{3} \mathrm{x}[\mathrm{OH}] / \\
\mathrm{mol} \mathrm{L}\end{array}$ & $10^{3} \mathrm{xk}_{\mathrm{obs}} / \mathrm{s}^{-1}$ & $\mathrm{I} / \mathrm{mol} \mathrm{L}^{-1}$ & $\begin{array}{c}10^{3} \mathrm{x}[\mathrm{OH}] / \\
\mathrm{mol} \mathrm{L}^{-1}\end{array}$ & $10^{3} \mathrm{xk}_{\mathrm{obs}} / \mathrm{s}^{-1}$ \\
\hline 0.03 & 6.33 & 6.01 & 0.2 & 39.9 & 11.7 \\
& 7.02 & 5.72 & & 50.3 & 14.7 \\
& 8.06 & 5.33 & & & \\
& 9.02 & 5.12 & & & \\
& 10.1 & 4.76 & 0.5 & 6.33 & 2.81 \\
& 11.0 & 4.65 & & 10.1 & 4.06 \\
& 12.5 & 4.50 & & 15.0 & 5.88 \\
& & & & 19.9 & 7.78 \\
& 6.33 & 4.54 & & 25.1 & 9.75 \\
& 9.02 & 4.07 & & 29.9 & 11.9 \\
& 12.1 & 4.01 & & 39.9 & 15.6 \\
& 15.0 & 4.18 & & 50.3 & 19.6 \\
& 18.2 & 4.53 & & & \\
& 19.9 & 4.76 & 1 & 6.33 & 3.30 \\
& 25.1 & 5.59 & & 10.1 & 5.06 \\
& & & & 15.6 & 7.75 \\
& 6.33 & 2.81 & & 19.9 & 9.86 \\
& 10.1 & 4.06 & & 29.9 & 14.7 \\
& 15.0 & 5.88 & & & \\
& 19.9 & 7.78 & 2 & 6.33 & 4.07 \\
& 25.1 & 9.75 & & 10.1 & 6.63 \\
& 29.9 & 11.9 & & 15.0 & 8.97 \\
& 39.9 & 15.6 & & 19.9 & 12.1 \\
& 50.3 & 19.6 & & 25.1 & 15.5 \\
& & & & & \\
& 6.33 & 3.00 & 3 & 4.89 & 3.31 \\
& 10.1 & 3.59 & & 6.93 & 5.07 \\
& 15.0 & 4.81 & & 8.98 & 6.29 \\
& 19.9 & 6.12 & & 11.0 & 7.97 \\
& 25.1 & 7.46 & & 13.1 & 9.59 \\
& 29.9 & 8.75 & & 14.9 & 10.8 \\
\hline & & & & &
\end{tabular}


$\mathrm{NaCl}$

\begin{tabular}{|c|c|c|c|c|c|}
\hline $\mathrm{I} / \mathrm{mol} \mathrm{L}^{-1}$ & $\begin{array}{c}10^{3} \mathrm{x}\left[\mathrm{OH}^{-}\right] / \\
\mathrm{mol} \mathrm{L}^{-1}\end{array}$ & $10^{3} \mathrm{xk}_{\mathrm{obs}} / \mathrm{s}^{-1}$ & $\mathrm{I} / \mathrm{mol} \mathrm{L}^{-1}$ & $\begin{array}{c}10^{3} \mathrm{x}\left[\mathrm{OH}^{-}\right] / \\
\mathrm{mol} \mathrm{L}^{-1}\end{array}$ & $10^{3} \mathrm{xk}_{\mathrm{obs}} / \mathrm{s}^{-1}$ \\
\hline \multirow[t]{6}{*}{0.03} & 5.05 & 8.18 & \multirow[t]{6}{*}{0.5} & 5.05 & 2.74 \\
\hline & 7.01 & 6.38 & & 7.01 & 2.84 \\
\hline & 8.98 & 5.36 & & 8.98 & 3.28 \\
\hline & 10.9 & 4.89 & & 10.9 & 3.83 \\
\hline & \multirow[t]{2}{*}{12.9} & \multirow[t]{2}{*}{4.70} & & 12.9 & 4.24 \\
\hline & & & & 14.9 & 4.78 \\
\hline \multirow[t]{6}{*}{0.05} & 5.05 & 6.29 & \multirow[t]{6}{*}{1} & 5.05 & 2.44 \\
\hline & 7.01 & 5.23 & & 7.01 & 3.00 \\
\hline & 8.98 & 4.62 & & 8.98 & 3.76 \\
\hline & 10.9 & 4.38 & & 10.9 & 4.50 \\
\hline & 12.9 & 4.29 & & 12.9 & 5.09 \\
\hline & 14.9 & 4.28 & & 14.9 & 5.89 \\
\hline \multirow[t]{6}{*}{0.1} & 5.05 & 4.85 & \multirow[t]{6}{*}{2} & 5.05 & 2.90 \\
\hline & 7.01 & 4.24 & & 7.01 & 3.96 \\
\hline & 8.98 & 3.91 & & 8.98 & 4.84 \\
\hline & 10.9 & 3.82 & & 10.9 & 5.96 \\
\hline & 12.9 & 3.96 & & 12.9 & 6.89 \\
\hline & 14.9 & 4.12 & & 14.9 & 8.09 \\
\hline \multirow[t]{6}{*}{0.2} & 5.05 & 3.59 & \multirow[t]{6}{*}{3} & 5.05 & 3.10 \\
\hline & 7.01 & 3.39 & & 7.01 & 4.24 \\
\hline & 8.98 & 3.48 & & 8.98 & 5.38 \\
\hline & 10.9 & 3.66 & & 10.9 & 6.71 \\
\hline & 12.9 & 3.89 & & 12.9 & 7.87 \\
\hline & 14.9 & 4.26 & & 14.9 & 9.38 \\
\hline
\end{tabular}




\begin{tabular}{|c|c|c|c|c|c|}
\hline $\mathrm{I} / \mathrm{mol} \mathrm{L}^{-1}$ & $\begin{array}{c}10^{3} \mathrm{x}\left[\mathrm{OH}^{-}\right] / \\
\mathrm{mol} \mathrm{L}^{-1}\end{array}$ & $10^{3} \mathrm{xk}_{\mathrm{obs}} / \mathrm{s}^{-1}$ & $\mathrm{I} / \mathrm{mol} \mathrm{L}^{-1}$ & $\begin{array}{c}10^{3} \mathrm{x}\left[\mathrm{OH}^{-}\right] / \\
\mathrm{mol} \mathrm{L}^{-1}\end{array}$ & $10^{3} \mathrm{xk}_{\mathrm{obs}} / \mathrm{s}^{-1}$ \\
\hline \multirow[t]{6}{*}{0.03} & 4.89 & 6.32 & 0.5 & 4.89 & 2.15 \\
\hline & 6.93 & 4.79 & & 6.93 & 2.69 \\
\hline & 8.98 & 4.25 & & 8.98 & 3.30 \\
\hline & 11.0 & 3.96 & & 11.0 & 4.06 \\
\hline & 13.1 & 3.84 & & 13.1 & 4.75 \\
\hline & & & & 14.9 & 5.31 \\
\hline \multirow[t]{6}{*}{0.05} & 4.89 & 4.52 & 1 & 4.89 & 2.45 \\
\hline & 6.93 & 3.82 & & 6.93 & 3.25 \\
\hline & 8.98 & 3.49 & & 8.98 & 4.16 \\
\hline & 11.0 & 3.46 & & 11.0 & 5.21 \\
\hline & 13.1 & 3.50 & & 13.1 & 6.13 \\
\hline & 14.9 & 3.64 & & 14.9 & 6.89 \\
\hline \multirow[t]{6}{*}{0.1} & 4.89 & 3.30 & 2 & 4.89 & 3.06 \\
\hline & 6.93 & 3.04 & & 6.93 & 4.47 \\
\hline & 8.98 & 3.08 & & 8.98 & 5.78 \\
\hline & 11.0 & 3.27 & & 11.0 & 7.07 \\
\hline & 13.1 & 3.46 & & 13.1 & 8.43 \\
\hline & 14.9 & 3.81 & & 14.9 & 9.84 \\
\hline \multirow[t]{6}{*}{0.2} & 4.89 & 2.54 & 3 & 4.89 & 3.52 \\
\hline & 6.93 & 2.63 & & 6.93 & 5.23 \\
\hline & 8.98 & 3.00 & & 8.98 & 6.66 \\
\hline & 11.0 & 3.45 & & 11.0 & 8.32 \\
\hline & 13.1 & 3.88 & & 13.1 & 9.63 \\
\hline & 14.9 & 4.29 & & 14.9 & 11.3 \\
\hline
\end{tabular}


$\mathrm{NaClO}_{4}$

\begin{tabular}{|c|c|c|c|c|c|}
\hline $\mathrm{I} / \mathrm{mol} \mathrm{L}^{-1}$ & $\begin{array}{c}10^{3} \mathrm{x}\left[\mathrm{OH}^{-}\right] / \\
\mathrm{mol} \mathrm{L}^{-1}\end{array}$ & $10^{3} \mathrm{xk}_{\mathrm{obs}} / \mathrm{s}^{-1}$ & $\mathrm{I} / \mathrm{mol} \mathrm{L}^{-1}$ & $\begin{array}{c}10^{3} \mathrm{x}\left[\mathrm{OH}^{-}\right] / \\
\mathrm{mol} \mathrm{L}^{-1}\end{array}$ & $10^{3} \mathrm{xk}_{\mathrm{obs}} / \mathrm{s}^{-1}$ \\
\hline \multirow[t]{6}{*}{0.03} & 5.05 & 8.72 & 0.5 & 5.05 & 2.77 \\
\hline & 7.01 & 6.74 & & 7.01 & 2.91 \\
\hline & 8.98 & 5.62 & & 8.98 & 3.31 \\
\hline & 10.9 & 5.01 & & 10.9 & 3.72 \\
\hline & 12.9 & 4.82 & & 12.9 & 4.22 \\
\hline & & & & 14.9 & 4.74 \\
\hline \multirow[t]{6}{*}{0.05} & 5.05 & 6.45 & 1 & 5.05 & 2.42 \\
\hline & 7.01 & 5.14 & & 7.01 & 2.90 \\
\hline & 8.98 & 4.48 & & 8.98 & 3.46 \\
\hline & 10.9 & 4.25 & & 10.9 & 4.11 \\
\hline & 12.9 & 4.16 & & 12.9 & 4.67 \\
\hline & 14.9 & 4.22 & & 14.9 & 5.39 \\
\hline \multirow[t]{6}{*}{0.1} & 5.05 & 4.78 & 2 & 5.05 & 2.05 \\
\hline & 7.01 & 4.05 & & 7.01 & 2.74 \\
\hline & 8.98 & 3.80 & & 8.98 & 3.42 \\
\hline & 10.9 & 3.81 & & 10.9 & 4.14 \\
\hline & 12.9 & 3.86 & & 12.9 & 4.88 \\
\hline & 14.9 & 4.09 & & 14.9 & 5.91 \\
\hline \multirow[t]{6}{*}{0.2} & 5.05 & 3.70 & 3 & 5.05 & 1.86 \\
\hline & 7.01 & 3.40 & & 7.01 & 2.55 \\
\hline & 8.98 & 3.42 & & 8.98 & 3.21 \\
\hline & 10.9 & 3.60 & & 10.9 & 3.87 \\
\hline & 12.9 & 3.82 & & 12.9 & 4.70 \\
\hline & 14.9 & 4.19 & & 14.9 & 5.56 \\
\hline
\end{tabular}


Table 2. Stoichiometric equilibrium constants, $\mathrm{K}^{*}$, for reaction (3) obtained from fitting of data in table 1 to eq $(5), \mathrm{T}=25^{\circ} \mathrm{C}$.

\begin{tabular}{cccccc}
\hline & $\mathrm{NaNO}_{2}$ & $\mathrm{NaCl}$ & $\mathrm{NaClO}_{4}$ & $\mathrm{KNO}_{2}$ & $\mathrm{KCl}$ \\
$\mathrm{I} / \mathrm{mol} \mathrm{L}^{-1}$ & $10^{-3} \mathrm{~K}^{*}$ & $10^{-3} \mathrm{~K}^{*}$ & $10^{-3} \mathrm{~K}^{*}$ & $10^{-3} \mathrm{~K}^{*}$ & $10^{-3} \mathrm{~K}^{*}$ \\
\hline 0.025 & $3.1 \pm 0.1$ & $3.6 \pm 0.1$ & $3.0 \pm 0.1$ & $4.9 \pm 0.2$ & $4.8 \pm 0.2$ \\
0.05 & $5.65 \pm 0.07$ & $6.0 \pm 0.2$ & $5.3 \pm 0.1$ & $8.8 \pm 0.1$ & $8.8 \pm 0.1$ \\
0.1 & $10.7 \pm 0.2$ & $9.4 \pm 0.2$ & $9.6 \pm 0.1$ & $17.9 \pm 0.3$ & $17.9 \pm 0.3$ \\
0.2 & $20 \pm 2$ & $18.5 \pm 0.3$ & $16.9 \pm 0.2$ & $40 \pm 2$ & $43 \pm 1$ \\
0.5 & $53 \pm 9$ & $47 \pm 2$ & $44 \pm 1$ & $218 \pm 68$ & $170 \pm 16$ \\
1 & $78 \pm 19$ & $141 \pm 15$ & $102 \pm 6$ & $411 \pm 311$ & $629 \pm 240$ \\
2 & $216 \pm 186$ & $385 \pm 107$ & $430 \pm 39$ & $301 \pm 252$ & \\
3 & $510 \pm 59$ & $727 \pm 63$ & $686 \pm 162$ & & \\
\hline
\end{tabular}

Table 3. Second order rate constants, $\mathrm{k}_{1}{ }^{*}$, obtained from fitting of data in table 1 to eq (5), $\mathrm{T}=25^{\circ} \mathrm{C}$.

\begin{tabular}{|c|c|c|c|c|c|}
\hline $\mathrm{I} / \mathrm{mol} \mathrm{L}^{-1}$ & $\begin{array}{c}\mathrm{NaNO}_{2} \\
\mathrm{k}_{1}^{*} / \mathrm{M}^{-1} \mathrm{~s}^{-1}\end{array}$ & $\begin{array}{c}\mathrm{NaCl} \\
\mathrm{k}_{1}^{*} / \mathrm{M}^{-1} \mathrm{~s}^{-1}\end{array}$ & $\begin{array}{c}\mathrm{NaClO}_{4} \\
\mathrm{k}_{1}^{*} / \mathrm{M}^{-1} \mathrm{~s}^{-1}\end{array}$ & $\begin{array}{c}\mathrm{KNO}_{2} \\
\mathrm{k}_{1}^{*} / \mathrm{M}^{-1} \mathrm{~s}^{-1}\end{array}$ & $\begin{array}{c}\mathrm{KCl} \\
\mathrm{k}_{1}^{*} / \mathrm{M}^{-1} \mathrm{~s}^{-1}\end{array}$ \\
\hline 0.025 & $0.127 \pm 0.005$ & $0.137 \pm 0.004$ & $0.123 \pm 0.005$ & $0.157 \pm 0.007$ & $0.132 \pm 0.005$ \\
\hline 0.05 & $0.158 \pm 0.001$ & $0.166 \pm 0.005$ & $0.152 \pm 0.003$ & $0.186 \pm 0.001$ & $0.162 \pm 0.002$ \\
\hline 0.1 & $0.198 \pm 0.002$ & $0.187 \pm 0.004$ & $0.185 \pm 0.002$ & $0.232 \pm 0.001$ & $0.203 \pm 0.002$ \\
\hline 0.2 & $0.240 \pm 0.001$ & $0.229 \pm 0.002$ & $0.220 \pm 0.002$ & $0.288 \pm 0.001$ & $0.261 \pm 0.002$ \\
\hline 0.5 & $0.316 \pm 0.002$ & $0.291 \pm 0.004$ & $0.288 \pm 0.002$ & $0.389 \pm 0.001$ & $0.349 \pm 0.002$ \\
\hline 1 & $0.362 \pm 0.003$ & $0.380 \pm 0.003$ & $0.345 \pm 0.002$ & $0.491 \pm 0.004$ & $0.461 \pm 0.003$ \\
\hline 2 & $0.472 \pm 0.003$ & $0.529 \pm 0.004$ & $0.372 \pm 0.001$ & $0.607 \pm 0.009$ & $0.648 \pm 0.004$ \\
\hline 3 & $0.546 \pm 0.002$ & $0.588 \pm 0.002$ & $0.351 \pm 0.002$ & $0.720 \pm 0.008$ & $0.749 \pm 0.005$ \\
\hline
\end{tabular}


Table 4 .

a) Stoichiometric equilibrium constants, $K^{*}$, for reaction (3)

\begin{tabular}{clll}
\hline Reference & Method & $\mathbf{K}^{*}$ & $\mathbf{I} /\left(\mathbf{m o l ~ L} \mathbf{L}^{-1}\right)$ \\
\hline \multirow{2}{*}{12} & $\begin{array}{l}\text { Polarography } \\
\text { spectrophotometry } \\
\text { this work }\end{array}$ & $\begin{array}{l}1.1 \times 10^{6} \\
1 \times 10^{6} \\
(1.7 \pm 0.2) \times 10^{5}\end{array}$ & $0.5(\mathrm{KCl})$ \\
\hline \multirow{2}{*}{6} & $\begin{array}{l}\text { Spectrophotometric } \\
\text { this work }\end{array}$ & $\begin{array}{l}(1.5 \pm 0.3) \times 10^{6} \\
(1.41 \pm 0.15) \times 10^{5}\end{array}$ & $1(\mathrm{NaCl}), 0.03\left(\mathrm{NO}_{2}^{-}\right)$ \\
\hline 4 & $\begin{array}{l}\text { polarography and spectrophotometry } \\
\text { this work }\end{array}$ & $\begin{array}{l}3.17 \times 10^{4} \\
(5.3 \pm 0.9) \times 10^{4}\end{array}$ & $0.5\left(\mathrm{NaNO}_{2}\right)$ \\
\hline \multirow{2}{*}{5} & Stopped flow & $1.26 \times 10^{4}$ & $0.35\left(\mathrm{NaClO}_{4}\right), 0.1\left(\mathrm{NaNO}_{2}\right) 23^{\circ} \mathrm{C}$ \\
& this work & $(1.69 \pm 0.02) \times 10^{4}$ & $0.2\left(\mathrm{NaClO}_{4}\right)$ \\
& this work & $(4.4 \pm 0.1) \times 10^{4}$ & $0.5\left(\mathrm{NaClO}_{4}\right)$ \\
\hline 11 & Stopped flow & $1.86 \times 10^{4}$ & $0.5\left(\mathrm{LiClO}_{4}\right)$ \\
\hline
\end{tabular}

b) Rate constants for the bimolecular reaction, $\mathrm{k}_{1} *$, see eq. (1)

\begin{tabular}{clll}
\hline Reference & Method & $\mathbf{k}^{*}{ }_{1} / \mathbf{M}^{-1} \mathbf{s}^{-1}$ & $\mathbf{I} /\left(\mathbf{m o l ~ L} \mathbf{L}^{-1}\right)$ \\
\hline 6 & $\begin{array}{l}\text { Spectrophotometry } \\
\text { this work }\end{array}$ & $0.55 \pm 0.01$ & $1(\mathrm{NaCl})$ excess $\mathrm{NO}_{2}^{-}$ \\
\hline 4 & $\begin{array}{l}-380 \pm 0.003 \\
\text { polarography }\end{array}$ & 0.216 & $0.5\left(\mathrm{NaNO}_{2}\right)$ \\
& this work & $0.316 \pm 0.002$ & \\
\hline 5 & Stopped flow & $0.202 \pm 0.002$ & $0.35\left(\mathrm{NaClO}_{4}\right), 0.1\left(\mathrm{NaNO}_{2}\right), 23^{\circ} \mathrm{C}$ \\
& $\begin{array}{l}\text { this work } \\
\text { this work }\end{array}$ & $0.220 \pm 0.002$ & $0.2\left(\mathrm{NaClO}_{4}\right)$ \\
\hline
\end{tabular}

Table 5. Interaction parameters of equation (10) at $25^{\circ} \mathrm{C}$

\begin{tabular}{lcccc}
\hline & $\boldsymbol{A}_{\boldsymbol{\theta}}$ & $\boldsymbol{A}_{\boldsymbol{1}}$ & $\boldsymbol{A}_{2}$ & $\boldsymbol{A}_{3}$ \\
\hline $\mathbf{K C l}$ & $-6.88 \pm 0.03$ & $0.5 \pm 0.2$ & $0.8 \pm 0.3$ & \\
$\mathbf{K N O}_{2}$ & $-6.71 \pm 0.09$ & $2.3 \pm 0.2$ & $-2.5 \pm 0.5$ & \\
$\mathrm{NaClO}_{4}$ & $-6.63 \pm 0.08$ & $-0.5 \pm 0.5$ & $4.9 \pm 0.8$ & $0.16 \pm 0.09$ \\
$\mathrm{NaCl}$ & $-6.69 \pm 0.06$ & $-0.3 \pm 0.3$ & $4.3 \pm 0.6$ & $0.12 \pm 0.07$ \\
$\mathrm{NaNO}_{2}$ & $-6.57 \pm 0.10$ & $1.6 \pm 0.6$ & $2 . \pm 1$. & $-0.3 \pm 0.1$ \\
\hline
\end{tabular}


Table 6. Interaction parameters of equation (14) at $25^{\circ} \mathrm{C}$

\begin{tabular}{lcccc}
\hline & $\boldsymbol{B}_{\boldsymbol{0}}$ & $\boldsymbol{B}_{1}$ & $\boldsymbol{B}_{2}$ & $\boldsymbol{B}_{3}$ \\
\hline $\mathbf{K C l}$ & $-2.60 \pm 0.02$ & $-0.2 \pm 0.1$ & $-1.6 \pm 0.2$ & $-0.009 \pm 0.03$ \\
$\mathbf{K N O}_{2}$ & $-2.459 \pm 0.006$ & $-0.27 \pm 0.04$ & $-1.41 \pm 0.06$ & $0.018 \pm 0.007$ \\
$\mathrm{NaClO}_{4}$ & $-2.66 \pm 0.01$ & $-0.42 \pm 0.09$ & $-1.7 \pm 0.1$ & $0.004 \pm 0.02$ \\
$\mathbf{N a C l}$ & $-2.54 \pm 0.02$ & $0.3 \pm 0.1$ & $-2.7 \pm 0.2$ & $-0.09 \pm 0.02$ \\
$\mathbf{N a N O}_{2}$ & $-2.62 \pm 0.03$ & $-0.4 \pm 0.2$ & $-1.5 \pm 0.3$ & $0.04 \pm 0.03$ \\
\hline
\end{tabular}

Table 7. Pitzer parameters from ref [18] at $25^{\circ} \mathrm{C}$

\begin{tabular}{lccc}
\hline & $\beta^{(0)}$ & $\beta^{(1)}$ & $C^{\phi}$ \\
\hline $\mathbf{K C l}$ & 0.04835 & 0.2122 & -0.00084 \\
$\mathrm{KNO}_{2}$ & 0.0151 & 0.015 & 0.0007 \\
$\mathrm{NaClO}_{4}$ & 0.0554 & 0.2755 & -0.00118 \\
$\mathrm{NaCl}$ & 0.0765 & 0.2664 & 0.00127 \\
$\mathrm{NaNO}_{2}$ & 0.0641 & 0.1015 & -0.0049 \\
\hline
\end{tabular}

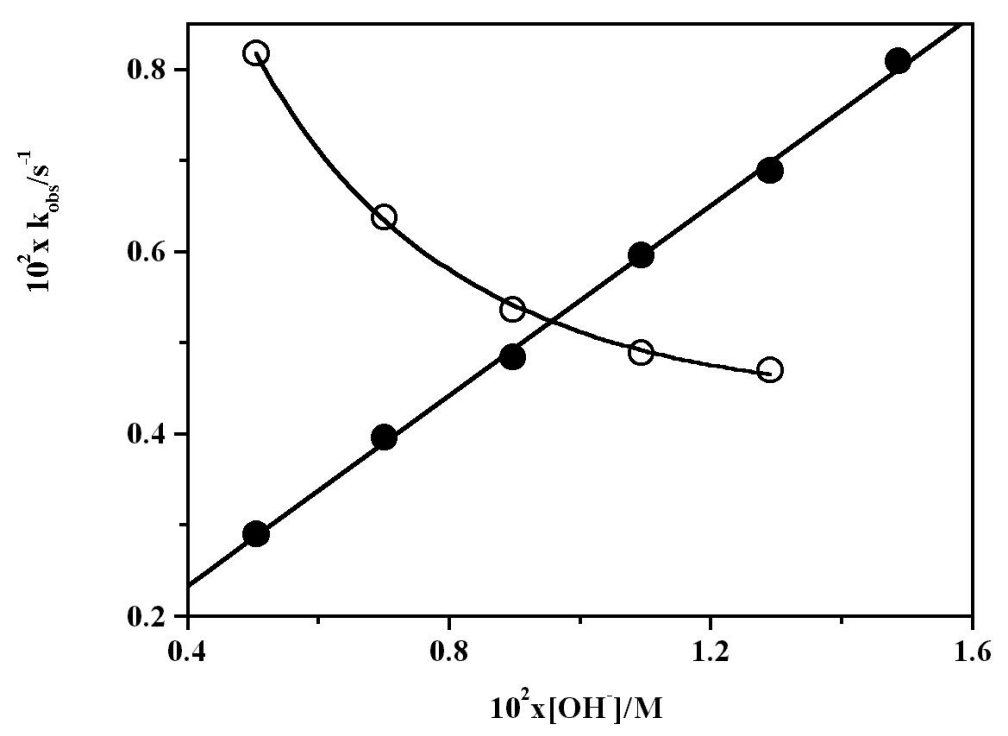

Fig. 1. Plot of $k_{o b s}$ vs. $\left[\mathrm{OH}^{-}\right]$for $\left[[\mathrm{Fe}(\mathrm{CN}) 5 \mathrm{NO}]^{2-}\right]=2.5 \times 10^{-4} \mathrm{M}$, $\left[\mathrm{NaNO}_{2}\right]=0.01 \mathrm{M}, 25^{\circ} \mathrm{C}$. Open circles $I=0.025 \mathrm{M}(\mathrm{NaCl})$, solid circles $I=2 \mathrm{M}(\mathrm{NaCl})$. The lines correspond to the theoretical behaviour derived from equation 5. 


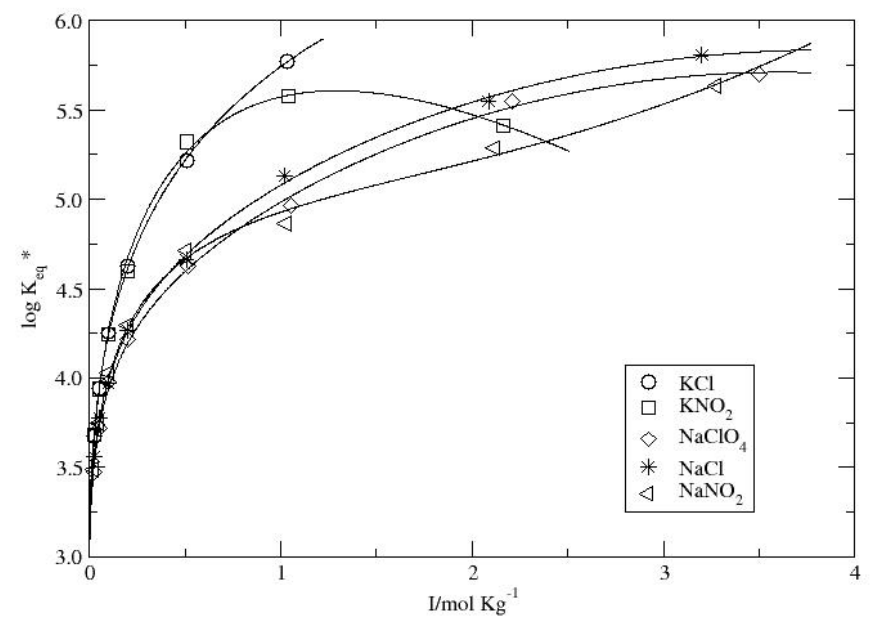

Fig.2 Stoichiometric equilibrium constant vs ionic strength: experimental data and Pitzer model

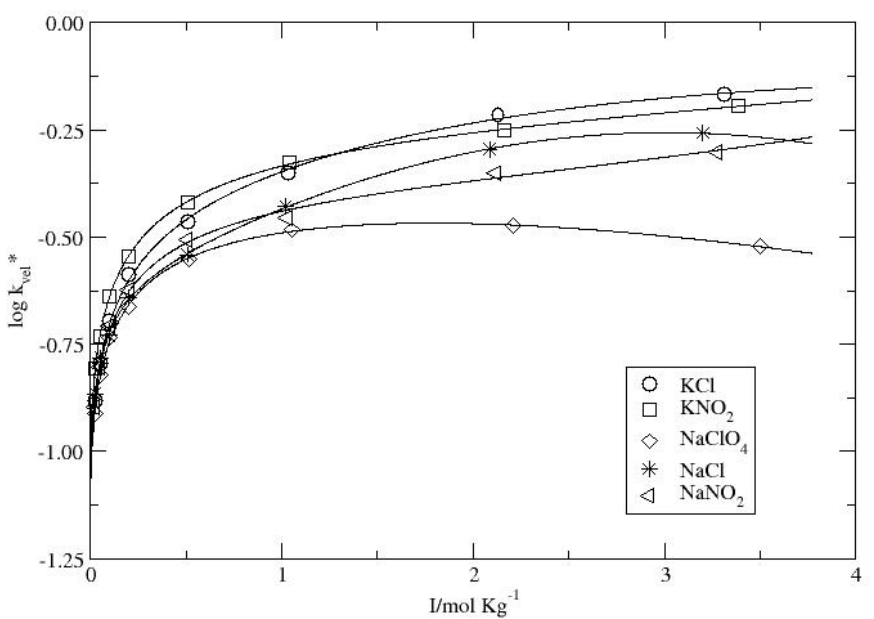

Fig.3 Rate constant vs ionic strength: experimental data and Pitzer model 